\title{
Mapping geological stages of climate-dependent iron and clay weathering alteration on lithologically unifor $m$ sedimentary units using Thematic Mapper imagery (Tertiary Duero Basin, Spain)
}

\author{
A. RIAZA, R. MEDIAVILLA and J. I. SANTISTEBAN \\ Instituto Tecnológico Geominero de España, Rios Rosas 23, 28003 Madrid, \\ Spain
}

\begin{abstract}
Weathering processes are responsible for slight surface mineralogical differences allowing the distinction between lithologically similar geological units using Thematic Mapper (TM) data. Two different stages throughout time of overlying iron alteration are notoriously distinctive on the imagery and laboratory spectra. Their diverse spectral behaviour follows the dominant iron hydroxide with kaolinite and carbonate crusts on the Pliocene Ochre Alteration typical of a humid warm climate, compared with the dominant nonhydratated iron oxides with smectite on the Miocene Red Alteration developed under a mediterranean dry climate. Iron materials with carbonate hinder appearance of the typical iron absorption features in the visible wavebands. Therefore, the iron weathering alteration coatings will be obscured on the imagery when it is developed on carbonate sediments or detritic sediments with carbonate cement or matrix. The presence of carbonate within the sediment as cement or alteration product decreases the overall reflectance of laboratory nonconsolidated rocks and the clay size fraction from rocks, apart from smoothing the $2200 \mathrm{~nm}$ absorption typical of $\mathrm{OH}$-bearing minerals. The presence of carbonate cement and carbonate crusts favours the differentiation of some units. Digital mapping through image processing of different series of digital data leads to a sequential masking of classes to produce a final map. The sequence of masking produces different maps which can be used as a tool to model aspects of the sedimentary basin and geological processes throughout time.
\end{abstract}

\section{Introduction}

Tertiary sedimentary basins cover $25 \%$ of the Iberian Peninsula. Their geological units consist of detrital nonconsolidated lithologically homogeneous, outcropping on a cultivated plain of small size fields. The countryside is shaped by smooth hills along wide-stepped flattened surfaces and cliffs dissected by river valleys. Water courses are mainly structurally controlled as parallel valleys with straight courses, anomalous elbows and angular confluences.

Satellite imagery in the visible and near-infrared $(0.4-2.5 \mu \mathrm{m})$ has been conventionally used to map hydrothermal alteration related to mineral deposits (Hunt and Ashley 1979, Prost 1980, Podwysocki et al. 1983, Townsend 1987, Fraser 1991). Limonitic alteration was one of the first features attracting the attention of geological remote sensing (Rowan et al. 1976, 1977, Abrams et al. 1977, Hunt and Ashley 1979, Segal 1982, 1983, Townsend 1987). Weathering processes produce the same minerals 
as hydrothermal alteration processes (Buckingham and Sommer 1983), and mask the spectral response of underlying rocks with coatings and internal mineralogical transformations (Lyon 1997). Using satellite imagery as a stratigraphic and structural tool has also assisted the study of sedimentary basins (Lang et al. 1990).

Aiming to map possible lithological differences, a Thematic Mapper (TM) im age has been digitally processed (TM 202-032-1, 28 August 1985) acquired during the driest period of the year to ensure the minim um possible interference from vegetation. Atmospheric correction has been performed by the minimum absorption method (Fraser 1991), and the intersection regression method (Crippen 1986), the latter showing better results in mapping different lithological units. Dense areas of vegetation were masked by thresholding the near-infrared/red ratio (TM bands 4/3) (Elvidge and Lyon 1985).

The use of band ratios has already been established for spectral difference detection in geology (Rowan et al. 1976, Hunt and Salisbury 1978, Rowan and Kahle 1982, Miller and Elvidge 1985). Several band ratio groups showing end values for every geological unit were selected, and classifications by the maximum likelihood algorithm were performed on the different selected band ratio groups, taking into account the statistics of each lithological unit. From the different classifications, the best representative of each geological unit was selected and gathered on a final map by sequential masking of one class over another.

The upper arcose unit of UTS P3 was better mapped classifying ratios 5/7, 2/1 and 1/7 (figure 9). The intermediate arcose and conglomerate unit with carbonate cement UTS P3 was better drawn taking the six visible and near-infrared TM channels atmospherically corrected. The Red Series of TSU N1 were mapped choosing ratios $4 / 3$ and $2 / 7$. The carbonate crusts were shown more clearly when classifying by channels $3 / 1,5 / 3,4 / 1,3 / 2$ and $2 / 4$. The Miocene red alterations were better outlined using ratios $2 / 7,2 / 1$ and $1 / 7$. The Pliocene ochre alteration was shown by ratios $5 / 4,4 / 7,5 / 1$ and $3 / 7$.

Laboratory spectral measurements were taken in the visible and near-infrared (400-2500 nm) to orientate digital image processing with a spectrophotometer provided with an integrating sphere and one nm spectral resolution, measuring diffuse reflectance versus a standard of barium sulphate. One hundred and twenty rock powder samples of clay size $(<2 \mu \mathrm{m})$ analysed by X-ray were spectrally measured. These samples were collected from known geological sites and not prejudiced by imagery interpretation. The different geological units shown on the imagery were sampled for soils, and spectra were measured after drying samples under atmospheric conditions and sieving through a $2 \mathrm{~mm}$ wide net.

\section{Geological setting}

The Basin of the River Duero is one of the largest sedimentary basins in the Iberian Peninsula flowing to the Atlantic Ocean. Rocks of Tertiary age outcrop on its south-western end and are represented by siliciclastic deposits, consisting mainly of conglomerate and sands, with scarce carbonate levels. The sequence can be divided into three megagroups (Santisteban et al. 1996a, b, Mediavilla in 1992) consisting of

Figure 1. (A) Geological map of the area studied in the Tertiary Duero Basin (Spain) (in Mediavilla 1992) and (B) stratigraphic column for the south-western Duero Basin (in Santisteban et al. 1996b). 
(a)

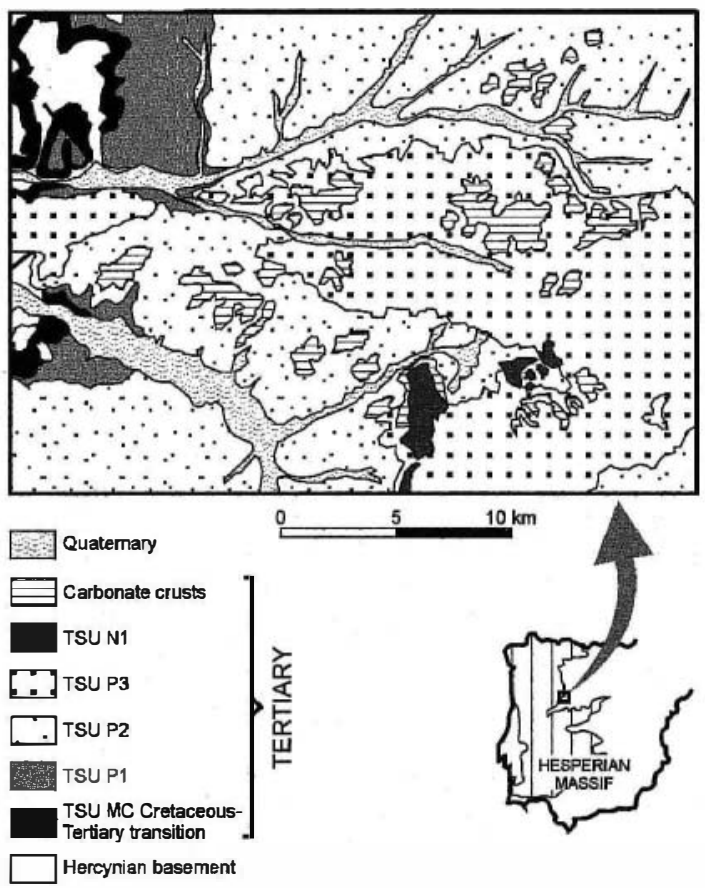

(b)

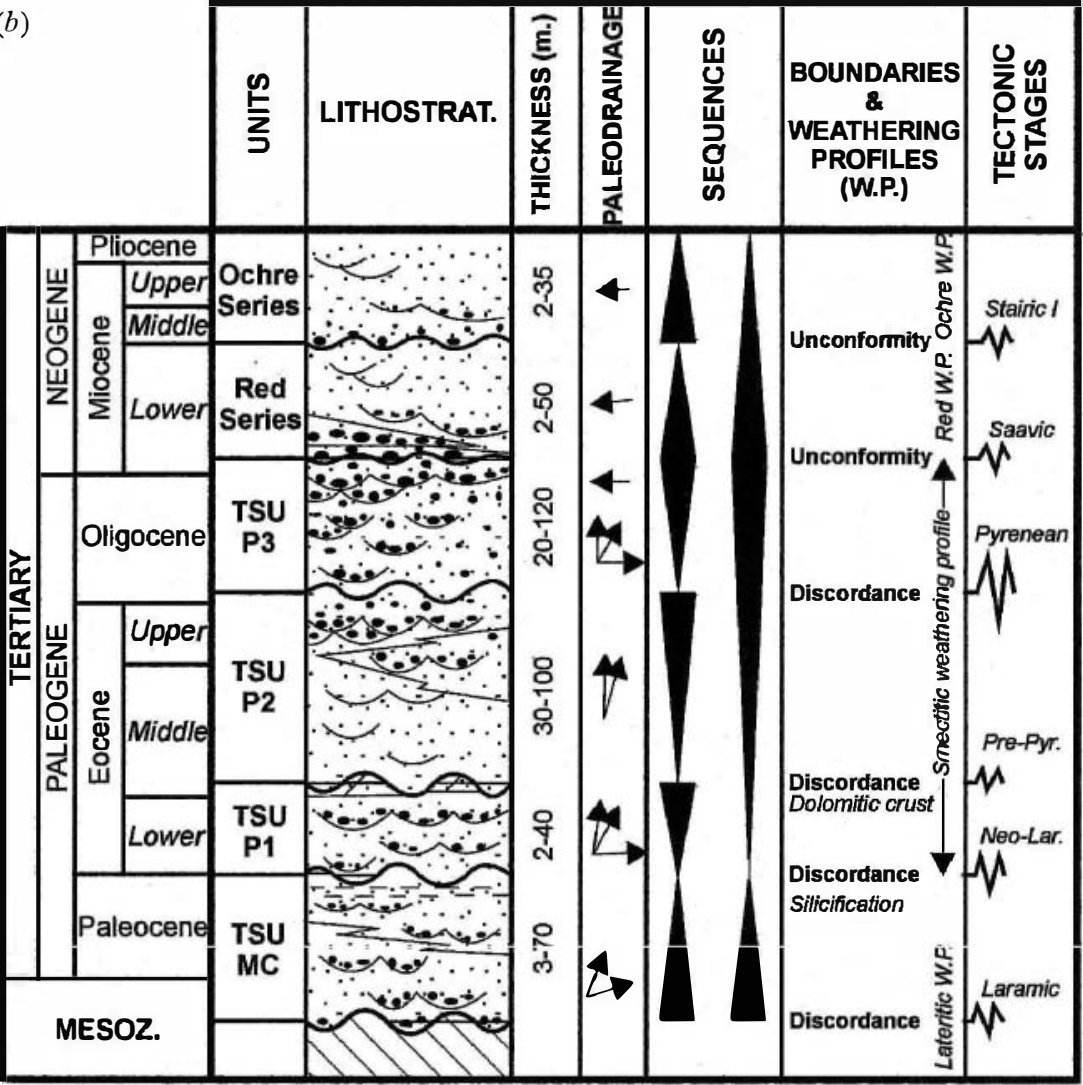



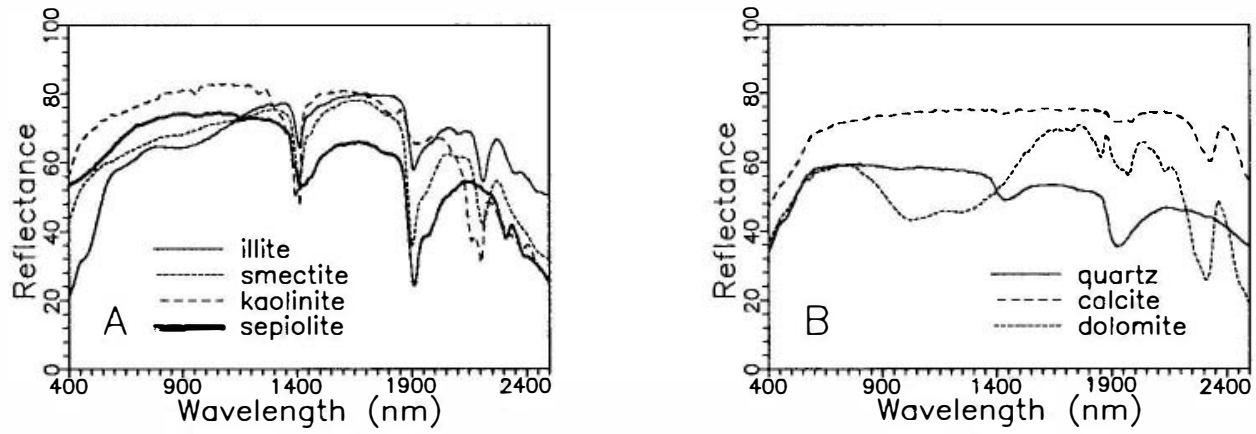

Figure 2. Spectral measurements in $(A)$ several clay minerals, $(B)$ carbonate and quartz (from the United States Geological Survey spectral library).

various tect•m•-sedimentary units (figure 1) linked to their relationship with the main stages of relief generation on the edges of the basin. The climate during the Tertiary changed from tropical humid to mediterranean, leaving its imprint on the sediments (Jiménez 1974).

A tropical alteration bed with kaolinite and iron minerals features at the bottom of the first group. The sediments overlying this bed (tectomo-sedimentary unit MC, figure 1) inherit a composition rich in kaolinite, exhibiting a silicification process of large superficial extent at the top (10YR 5/3 brown, when nonconsolidated, 10YR $7 / 2$ light grey, when hardened). This group is attributed to late Mesozoic stage during which a continental sedimentation in an alluvial environment prevailed. The age of this group is Upper Cretaceous?-Palaeocene.

The materials of the second group (tectomo-sedimentary units P1, P2 and P3, figure 1) have an arkosic to subarkosic-lithicarkosic composition and a smectitic matrix. The tectomo-sedimentary unit P1 (10Y R 4/4 dark yellowish brown), overlain by an important carbonate-clay crust and tectomo-sedimentary unit P3 are characterized by their high content of feldspar and clay matrix. The tectomo-sedimentary unit P3 (10YR 5/4 yellowish brown) is rich in metamorphic lithic fragments and has a very generalized dolomite carbonate cementation. The main relief around the edge of the basin developed during the formation of the second group. The deposits depict a sedimentation history in an alluvial environment evolving from sinous alluvial systems in low slope gradient areas (tectomo-sedimentary unit P1, 10YR 4/4 dark yellowish brown) to braided systems on mountain areas (tectomo-sedimentary unit P3) (figure 1). The age of the second group spans from lower Eocene to Oligocene.

The third group consists of sediments with mainly lithic composition and an important content of clay matrix. Alteration processes took place during the period of deposition both on the borders and in the interior of the basin, resulting in two units. During the first stage (Red Series, figure 1, 10YR 3/4 dark yellowish brown) an alteration typical of a mediterranean climate was produced with the growth of smectite and fixation of iron oxides (rubefaction). This gives a typical red colour to the sediment (5YR 4/6 yellowish red), as well as carbonate crusts $(2.5 \mathrm{Y} 4 / 4$ olive brown). The second unit (Ochre Series, figure 1) shows a more humid climate detected by a kaolinite and iron oxide-hydroxide alteration bed, giving the sediment a typical ochre colour (10YR 4/6, dark yellowish brown). This Neogene age group represents a sedimentation on alluvial fans and fluvial systems in the frame of a readjusting 


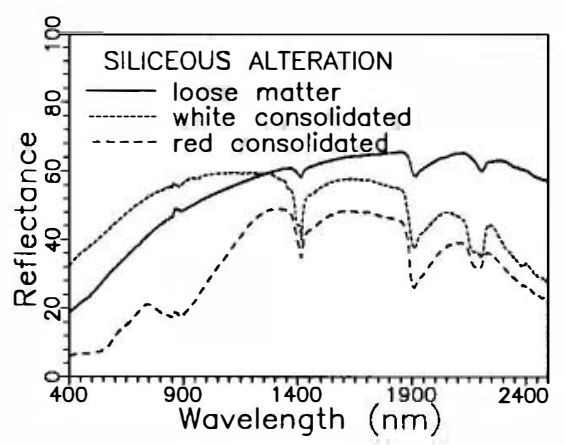

Figure 3. Spectral measurements on Palaeocene silicic altered materials (figure 2), with differences between loose material, and hardened material of white and red colour.

relief by erosion and trend to the lowering of the base level. The result is a suite of sediments outcropping on sequentially lower terraces on the slopes of the valley.

\section{Spectral properties of sediments and alteration minerals}

\subsection{Minerals}

Clay minerals have drawn great attention to spectral studies both in the laboratory and image data (Hunt and Salisbury 1970, Hunt et al, 1973, Lindberg and Snyder 1972). Clays included on sediments and alterations mapped in the area show a strong spectral absorption feature on $2200 \mathrm{~nm}$, except that of atapulgite (figure 2(A)). Apart from kaolinite, they also show absorptions on $1900 \mathrm{~nm}$. Kaolinite, sepiolite and atapulgite present several minor minima between 2200 and $2300 \mathrm{~nm}$, which are absent on the spectral response of montmorillonite and illite (Hunt 1979, Lyon and Honey 1989).

Goethite, in common with all iron mineral, shows its distinctive features in the visible (White and Keester 1966, Hunt and Salisbury 1971 b, Peters 1983, Townsend 1987 ) with a minimum at $475 \mathrm{~nm}$, a deep fall towards the blue from the longer visible wavelengths, and a wide depression between 800 and $1200 \mathrm{~nm}$. The typical OHbearing mineral absorption bands in the infrared are absent in goethite. The grain size of the sample adjusts the overall spectral response of iron oxides and hydroxides in contrast to silicates. Therefore, the overall reflectance in iron oxides and hydroxides decreases with grain size.

Carbonate registers a moderately wide absorption at $2300 \mathrm{~nm}$, plus several minor minima between 1800 and $2000 \mathrm{~nm}$ (Hunt and Salisbury 1971a, Hunt 1979, Lyon and Honey 1979) (figure 2(B)). Such absorptions allow the differentiation between siliceous and carbonated areas. Carbonates and $\mathrm{OH}$-bearing minerals show diagnostic spectral features in the same wavelength ranges when working with low spectral resolution data. The spectral properties of mixtures of different percentages of the same two components do not reproduce a mathematical relationship with the spectra of the individual pure components (Singer 1981). The texture of carbonate of the same mineralogical composition is also reflected on a different spectral response (Crowley 1986). Therefore, the presence of silica, carbonate, or both of them in the same area or sample will interfere with the identification of such components. 


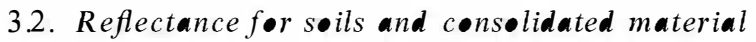

Most of the sediments outcropping in basins of Tertiary age are not consolidated. Only the carbonate crusts at the top of arkosic units and the siliceous alterations are hardened in the study area. Therefore, the spectral response offered to scanner sensors is similar to the general response of soils and does not resemble the spectra registered from powdered clay size samples used for X-ray diffraction nor to those of consolidated rocks.

The siliceous alterations are very distinct on the imagery, both for their high overall reflectance and the geomorphological ridges of hardened materials. These hardened rocks show spectra with typically asymmetrical absorption features at 1400, 1900 and $2200 \mathrm{~nm}$ with thresholds at 1350,1380 and $1930 \mathrm{~nm}$ and a shoulder between 1150 and $1170 \mathrm{~nm}$ (figure 4) (Hunt and Ashley 1979). Less important, a shoulder on $2400 \mathrm{~nm}$ can be seen. Very often, the hardened siliceous rocks are ferruginous (Rowan et al. 1977). Then, the minima on 475 and $550 \mathrm{~nm}$ join a wider and clear minimum centred at $900 \mathrm{~nm}$ due to the iron contents (figure 3 ).

The presence of carbonate, whether on crusts or as cement (tectomo-sedimentary unit P2) decreases the overall reflectance, regardless of the lighter colour of the material and also smoothens the $2200 \mathrm{~nm}$ absorption feature (figure $4(A)$ ).
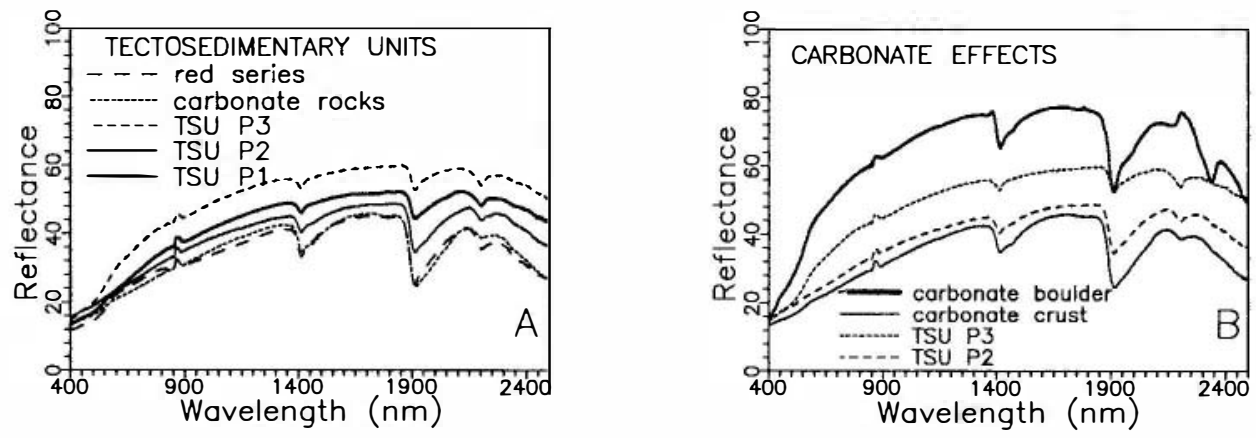

Figure 4. (A) Spectral measurements on nonconsolidated materials from the different tectomo-sedimentary units in the area of study, including carbonate crusts at the top of the tectomo-sedimentary unit P2 and P3. (B) Spectral measurements on the tectomosedimentary units where carbonate crusts are developed, with differences on boulders coming from hardened materials and nonconsolidated material.
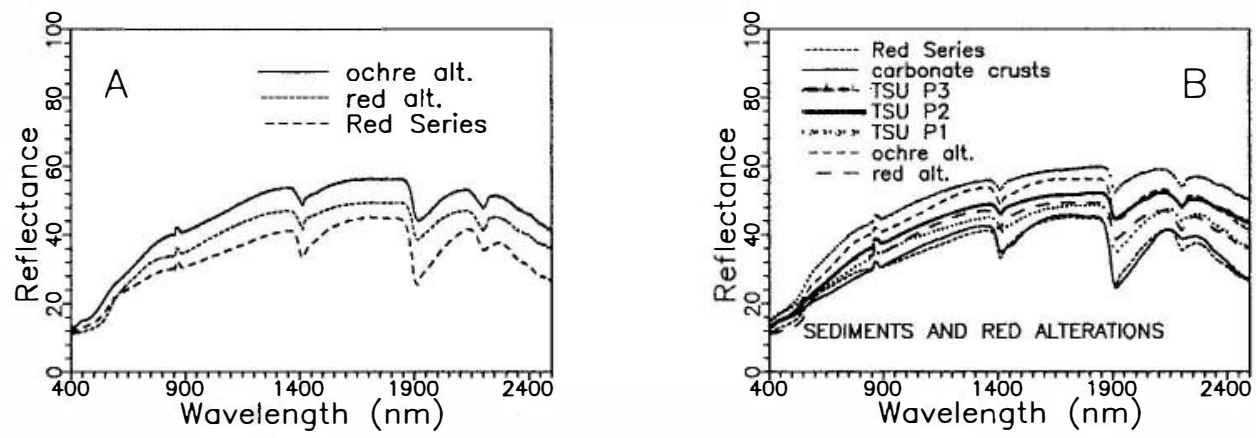

Figure 5. (A) Spectral measurements on nonconsolidated ferruginous materials (Red Series) and altered surfaces. (B) Spectral measurements on tectomo-sedimentary units and Miocene red alterations and Pliocene ochre alterations before their deposit. 
The carbonate boulders, very abundant as loose material where carbonate crusts outcrop, provide a most distinctive strong absorption at $2350 \mathrm{~nm}$ (figure $4(B)$ ). This is only shown on the spectral response of soils on the smoothing of the $2200 \mathrm{~nm}$ absorption. The white colour of carbonate boulders gives a high overall reflectance, which is registered by the TM sensor.

The lower Miocene red alterations and the contemporaneous Red Series (tectomo-sedimentary unit N1) are very similar in overall reflectance to the carbonate crusts. They show the typical iron absorptions in the visible on red materials, and the smoothed $2200 \mathrm{~nm}$ absorption on carbonates (figure 5(B)). Contrary to the imagery, the Pliocene ochre alterations with iron hydroxide show a higher overall reflectance than the $M$ iocene red alteration with iron oxides, but the $475 \mathrm{~nm}$ threshold is more strongly emphasized for the Pliocene ochre alteration than for the Miocene red alteration (figure $5(A)$ ).

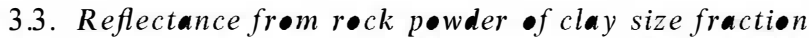

The three tectomo-sedimentary units P2, P1 and N1, the dominant rock exposures in the mapped area, show very similar absorption features on their laboratory spectral response (figure 6). The tectomo-sedimentary unit P2 consisting of conglomerate and arkosic sands with carbonate cement shows a stronger absorption on $1900 \mathrm{~nm}$ than tectomo-sedimentary unit P3. The carbonate cement is spectrally distinguished by a smoothed $2200 \mathrm{~nm}$ absorption, a wavy increase in reflectance from 2200 to $2300 \mathrm{~nm}$ and a steeper descent towards longer wavelengths. The presence of smectite is particularly evident in tectomo-sedimentary unit P2 not only by a stronger $1900 \mathrm{~nm}$ absorption, but by two thresholds on the ascent to longer wavelengths, both at the $1400 \mathrm{~nm}$ and the $1900 \mathrm{~nm}$ absorption.

The intrasedimentary carbonate crusts at the top of the tectomo-sedimentary units P2 and P3 show the same features due to carbonate content within the 2000$2500 \mathrm{~nm}$ wavelength range (figure $7(A)$ ). The absorption at $1400 \mathrm{~nm}$ is smoothed, due to the relatively poor quartz and $\mathrm{OH}$-bearing mineral content. Also, samples with carbonate hinder the exhibition of the typical iron absorptions in the visible wavelengths.

On single samples belonging to the tectomo-sedimentary unit P2 where calcite or dolomite are abundant (figure $7(A)$ ), the samples with large quantities of dolomite show sharpened absorption features between 1800 and $2500 \mathrm{~nm}$. These can be

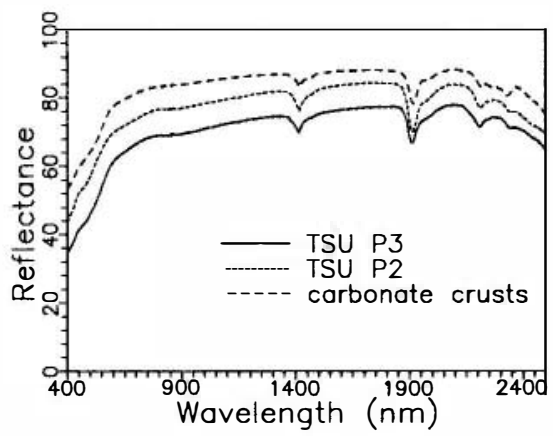

Figure 6. Spectral measurements on clay size fraction under $2 \mu \mathrm{m}$ on the tectomosedimentary units widely outcropping throughout the area of study, with expression of the intrasedimentary carbonate crusts at their top. 

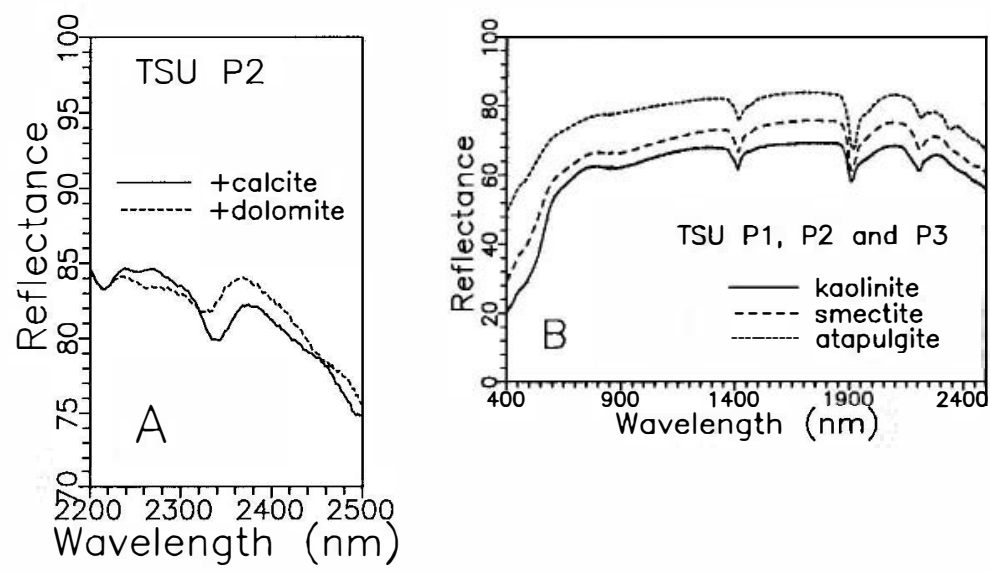

Figure 7. (A) Spectral measurements on clay size fraction under $2 \mu \mathrm{m}$ of the tectomosedimentary unit P2 with dominant calcite or dolomite. (B) Spectral measurements on clay size fraction under $2 \mu \mathrm{m}$ of the tectomo-sedimentary units P1, P2 and P3 with dominant contents on kaolinite, smectite or atapulgite.

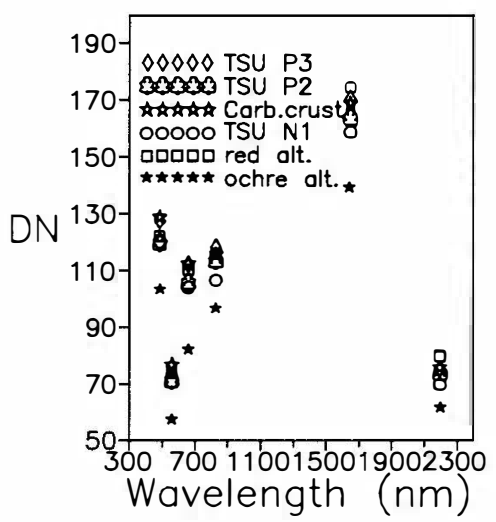

Figure 8. Digital numbers from TM images on control fields belonging to the different tectomo-sedimentary units and alterations.

summarized on a deep and narrow absorption on $1900 \mathrm{~nm}$ with a threshold on 1950 and $2000 \mathrm{~nm}$, and smooth minima on 2200 and $2260 \mathrm{~nm}$. The abundance of dolomite is shown to be evident with the shift from the $2350 \mathrm{~nm}$ calcite-bearing absorption towards $2330 \mathrm{~nm}$ (figure $7(A)$ ).

Unfortunately, the area with outcrops of siliceous alteration, Red Series and Miocene red sands with illite and kaolinite is not extensive enough to study the spectral response on imagery. The laboratory studies on samples selected by the quantitative $X$-ray analysis of clay fraction show slightly distinct features with a very similar general spectral response.

The spectral response from clay-size samples consisting of dominant kaolinite and atapulgite show lower and higher overall reflectance than the spectra with dominant smectite, placing smectite in an intermediate position between kaolinite and atapulgite (figure $7(B)$ ). The presence of atapulgite on the clay fraction is spectrally indicated by a deepening on the $1900 \mathrm{~nm}$ absorption and an enhancement of 
the shoulder between 1950 and $2000 \mathrm{~nm}$. This is accompanied with smoothing of the $2200 \mathrm{~nm}$ absorption and the presence of typical carbonate absorption irregularities on longer wavelengths. Where kaolinite is dominant, the $1900 \mathrm{~nm}$ absorption is shallower. However the $2200 \mathrm{~nm}$ is emphasized and the remaining features towards longer wavelengths are closely identified to atapulgite-dominant spectra.

Such differences contribute to the identification on the imagery of five main erosion stages which took place from Palaeozoic times on the Hesperian Massif of the Iberian Peninsula.

\section{Expression of geological units on the imagery}

A preliminary view of a false colour composite of bands 4,7 and 5 (BRG) shows a plain covered with small cultivated fields with two topographically high areas to the west where shrubs and sparse evergreen oaks grow. The few granite outcrops occur in the elevated areas, and their distinctive geomorphology is reflected as a finer texture on the imagery. Different areas are distinguished within the plain according to different field size and pattern which are related to the underlying lithology.

The study area is subdivided into four different aspect sections by means of principal component analysis on the six visible and near-infrared TM bands, after vegetation masking. The lithological separation is shown by the colour composite of the principal components 2, 4 and 3 (BRG). This composite illustrates the areas with more intense red alteration and the Red Series deposits (tectomo-sedimentary unit N1), whereas areas covered by tectomo-sedimentary units P1 and P2 remain homogeneous. The composite of the more advanced principal components 4, 6 and 5 indicates more clearly, though diffuse, the preferred areas for red alteration.

\subsection{Tectanosedimentary units $P 1, P 2$ and $P 3$}

The ratio of band $5 / \mathrm{b}$ and 7 is conventionally used to show the clay mineral content. Density slicing of this ratio demonstrates higher values for clays in tectomosedimentary units P2 and P3, excluding P1, perhaps due to an extensive upper crust of dolomite and clays.

Further iscrimination in other colour composites was limited at this point due to the presence of small cultivated fields and the complex geological relationships. Therefore, training fields were chosen in representative areas of the imagery to perform quantitative statistic evaluation of different composites with the aim to distinguish lithologies (Miller and Elvidge 1985). Initially, a classification was performed on the six visible and near-infrared TM bands which were atmospherically corrected by the dark value subtraction method. This classification illustrated tectomo-sedimentary units P2 and P3 with some accuracy, and carbonate crusts developed by late diagenesis.

\subsection{Late diagenetic events}

The ratio between TM bands $3 / 1$ is also known to reflect iron content (Rowan et al. 1977). The areas showing higher values on $3 / 1$ ratio are restricted to the hills where red alterations are better developed. Density slicing of this ratio also shows a mist of small spots over areas covered by tectomo-sedimentary unit P2, with the exception of the wider areas along the la Encina stream, which host the scarce Miocene Red Series outcrops. 
Ratios $3 / 2$ and 4/1 were tested to provide information about iron contents (White et al. 1992), but principal com ponents of this ratios not add any new information.

Both red alteration and carbonate crusts are late events overprinted on the previously deposite arkosic units. Following this, the Red Series unit was later deposited by erosion of the above units. Mineralogical changes are widespread, shown to be fragmented on the surface, and overlying the rocks where they are developed (Lyon 1997). Therefore, the spectral response on the imagery reproduces a fragmented spatial result. Also, alteration events show different spectral behaviour when affecting different underlying lithologies and geological units (Rivard et al. 1992, Riaza et al. 1995).

It was attem pted to classify different ratio groups selected after ex amining extreme values for different lithologies performed on bands corrected by the regression intersection method. This showed better results in mapping Miocene red alteration outcrops and their contem poraneous Miocene Red Series (tectomo-sedimentary unit N1) deposits. In contrast, the subtle colour and mineralogical composition differences among tectomo-sedimentary units P2 and P3 dominate the classification performed on the six visible and near-infrared bands.

The quantitative analysis, based on control fields belonging to well developed red alteration areas produces two well defined families of values. The red Miocene alteration extends over both tectomo-sedimentary units P2 and P3 in a very fragmented superficial pattern, corresponding to their composition of nonhydratated iron oxides. It is better developed on tectomo-sedimentary unit P2 comprising conglomerate, arkose and carbonate cement. This carbonate cement prevents the weathering processes from rapidly affecting the sediment, so the red colour is more intense on the surface of tectomo-sedimentary unit P2 than on tectomo-sedimentary unit P3, where there is more infiltration and the ferruginous processes are more rapidly extended in depth.

The laboratory spectra demonstrate that carbonate-bearing samples lack the development of the typical absorption features of iron. This way, the spectral properties of mineral groups shown in the laboratory help us to understand the spectral characteristics of the imagery which are produced by geological processes.

The occurrence of the second iron alteration unit is more homogeneous and restricted to areas towards the north and south-west. This is the Pliocene ochre alteration in which goethite is dominant over nonhydratated iron oxides. It outcrops along the westwards drainage flow direction during the Pliocene, when the current drainage flow was established.

Both red and ochre alterations show the most extreme values among the examined lithologies on the imagery. The Miocene red alteration tends towards higher reflectance values in the group, with values closer to the other tectomo-sedimentary units (figure 8). On the contrary, the Pliocene ochre alteration has distinctly lower reflectance than the remainder of the units. Ratios involving both visible and the near-infrared bands are more effective than conventional ratios in differentiating between the red and ochre iron alterations, or to distinguish them from other lithological units. Clay minerals involved in the alteration processes and cements on the underlying tectomo-sedimentary units contribute to such variations on the expected spectral response relying in mineralogically pure samples.

A unique image was produced by masking one unit after the other arising from the classification (figure 9). This showed better results for each unit, allowing the construction of a summary map. The change in the sequence of masking results in 


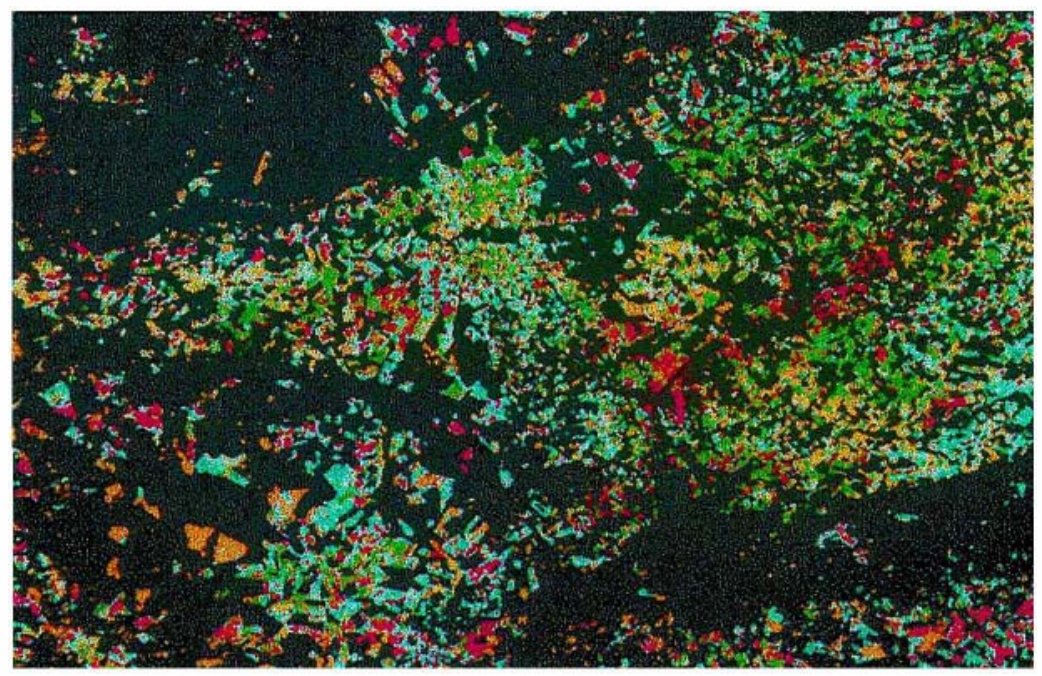

(a)

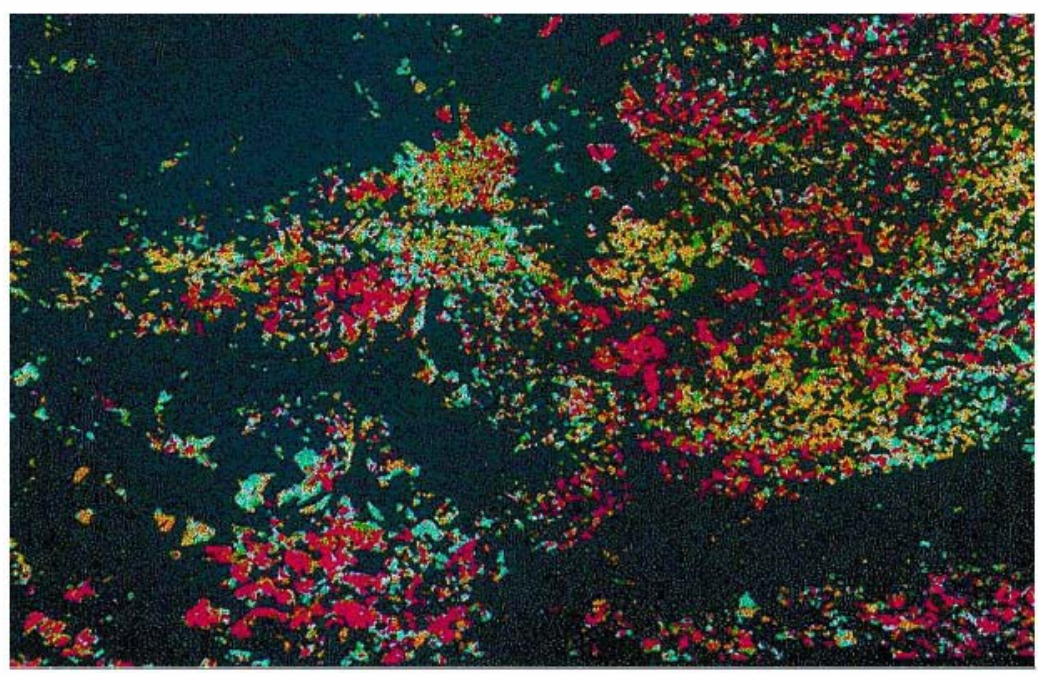

(b)

Figure 9. Map resulting from sequential masking of geological units obtained by classifying different series of data from TM channels after atmospheric correction by the regression intersection method (Crippen 1987). Cyan, tectomo-sedimentary unit P2 (six visible and near-infrared TM bands); yellow, tectomo-sedimentary unit P3 (5/7, 2/1 and 1/7); dark red, tectomo-sedimentary unit N1 (4/3 and 2/7); green, carbonate crusts $(3 / 1$, $5 / 3,4 / 1,3 / 2$ and 2/4); light red, Miocene red alterations (2/7, 2/1 and 1/7); orange, Pliocene ochre alterations $(5 / 4,4 / 7,5 / 1$ and $3 / 7)$. (A) Masking sequence without reference to the chronology of geological events. The sedimentary units and alterations are represented by their corresponding area $(B)$, masking according to the chronology of geological events. The two late iron alteration and contemporaneous deposits represented by reddish and orange colours dominate the area of study.

a series of final maps. When masking is performed following the chronological sequence of geological events (figure $9(A)$ ), a map is produced which shows fundamentally the two late iron alteration events and Red Series deposits only. This map 
faithfully represents the actual aspect of the outcrops where the late iron alteration and deposits dominate the surface. The extent of carbonate crusts and the previously deposited tectomo-sedimentary units is then obscured. To discriminate older tectomo-sedimentary units and geological events, a different masking sequence is necessary (figure $9(B)$ ). This way, digital image processing can be used as a dynamic tool to reproduce geological processes and modelling the aspect of sedimentary basins on different geological stages throughout time.

\section{Conclusions}

Thematic Mapper imagery allows the distinction between lithologically similar geological units due to slight surface mineralogical differences caused by weathering processes.

The presence of carbonate cement favours the differentiation of tectomosedimentary units $\mathrm{P} 2$ and P3. The two intrasedimentary carbonate crusts at the top of both units are also shown to be mappable.

Two different stages throughout time of overlying iron alteration are notoriously distinctive on the imagery and laboratory spectra. Their diverse spectral behaviour follows the dominant iron hydroxide with kaolinite and carbonate crusts on the Pliocene ochre alteration typical of a humid warm climate, and are most distinct and characteristic on the imagery, compared with the dominant nonhydrated iron oxides with smectite on the Miocene red alteration developed under a mediterranean dry climate.

Iron materials with carbonate hinder appearance of the typical iron absorption features in the visible wavebands. Therefore, the iron weathering alteration coatings will be obscured on the imagery when it is developed on carbonate sediments or detritic sediments with carbonate cement or matrix.

The presence of carbonate within the sediment as cement or alteration product decreases the overall reflectance of laboratory nonconsolidated rocks and the clay size fraction from rocks, apart from smoothing the $2200 \mathrm{~nm}$ absorption typical of H-bearing minerals.

Digital mapping through image processing of different series of digital data leads to a sequential masking of classes to produce a final map. The sequence of masking produces different maps which can be used as a tool to model aspects of the sedimentary basin and geological processes throughout time.

\section{Acknowledgements}

The geological mapping of A. Martín-Serrano, his knowledge on processes and diagenesis on the Tertiary basins suggested the initiation of this work. Discussions with R. Pereira contributed to enrich the image evaluation and thoughts about the use of image processing related to geological processes. L. Pascual and A. Tomás were invaluable helpers in the use of the laboratory spectrophotometer to which access was provided by J. L. Navarro.

\section{References}

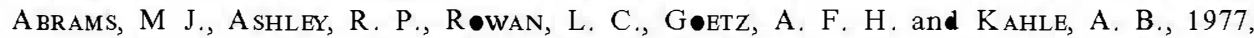
Mapping of hydrothermal alteration in the Cuprite mining district, Nevada, using aircraft scanner images for the spectral region 0.46 to $2.36 \mu \mathrm{m}$. Ge•løgy, 5, 713-718.

BuckingHAM, W. F., and SøMmER, S. E., 1983, Mineralogical characterization of rock surfaces formed by hydrothermal alteration and weathering. Application to remote sensing.

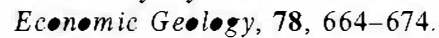


CRIPPEN, R. E. 1986, The regression intersection method of adjusting image data for band ratioing. Proceedings Fifth Thematic Cønference: Remøte Sensing for Exploration Ge•l•gy, Reno, Nevada, Sept 29-Oct 2, 407-416.

CRøWLEY, J. K., 1986, Visible and near-infrared spectra of carbonate rocks: reflectance variations relate to petrographic texture and impurities. J•urnal $\bullet$ Gephysical Research, 91, 5001-5012.

Elvidge, CH. D., and Y Lyøn, R. J. P. 1985, Estimation of the vegetation contribution to the $1.65 / 2.22 \mu \mathrm{m}$ ration in airborne thematic-mapper imagery of the Virginia Range,

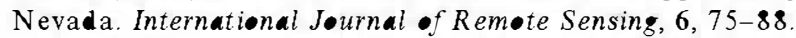

FRASER, S. J., 1991, Discrimination and identification of ferric oxides using satellite Thematic

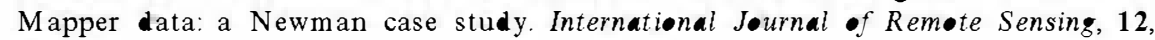
$635-641$.

Hunt, G. R., 1979, Near-infrared (1.3-2.4 $\mu \mathrm{m})$ spectra of alteration minerals. Potential for use in remote sensing. Gephysics, 44, 1974-1986.

Hunt, G. R., and Ashley, R. P., 1979, Spectra of altered rocks in the visible and near-infrared.

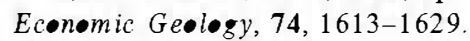

Hunt, G. R., and SAlisbury, J. W., 1970, Visible and near-infrared spectra of minerals and

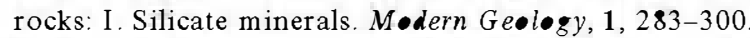

Hunt, G. R., and SAlisbury, J. W., 1971, Visible and near-infrared spectra of minerals and

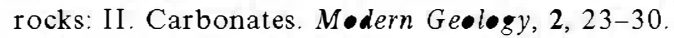

HUNT, G. R., and S ALISBURY, J. W ., 1978, Assessment of Landsat filters for rock type discrimination, based on intrinsic information in laboratory spectra. Gephysics, 43-4, 738-747.

Hunt, G. R., Salisbury, J. W., and Lenh•F, J., 1971, Visible and near-infrared spectra of

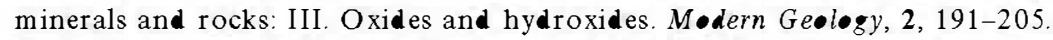

Hunt, G. R., SAlisbury, J. W., and Lenh•F, J., 1973, Visible and near-infrared spectra of

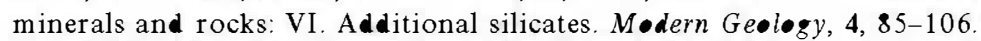

Jimenez, E., 1974, Iniciación al estudio de la climatología del Paleógeno de la Cuenca del

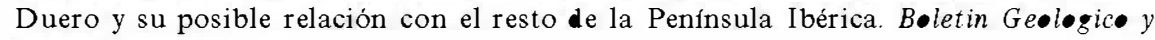
Miner $\bullet$ 85, 518-524.

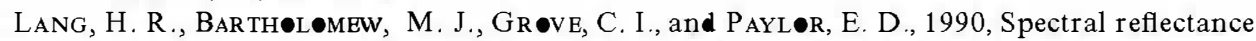
characterization $(0.4$ to 2.5 and 8.0 to $12.0 \mu \mathrm{m})$ of Phanerozoic Strata, Wind River

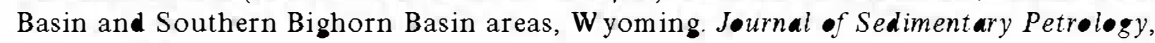
60, 504-524.

LindBeRG, D., and SNYDER, D. G., 1972, Diffuse reflectance spectra of several clay minerals. American Mineralogist, 57, 485-493.

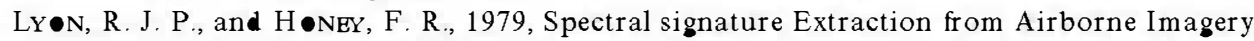
using the Geoscan MkII Advanced Airborne Scanner in the Leonora, Western

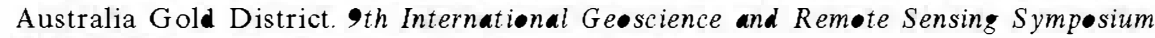

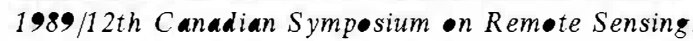

LY॰N, R. S. P., 1997, Weathering products and other coatings on rock surfaces: problems with airborne scanner imagery (RSS97-112). 23rd Annual Conference and Exhibition of the

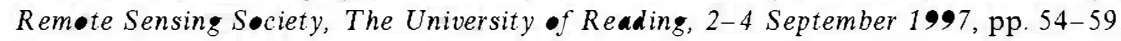

Martin-Serrane, A., 1986, El relieve de la región occidental zamorana. Un modelo de evolución geomorfológica del borde hespérico. $\mathrm{PhD}$ Thesis, University Complutense of Madrid (Publications Instituto de Estudios Zamoranos 'Florián de Ocampo', Consejo Superior de Investigaciones Cientificas, Zamora, Sapin), 1989, $311 \mathrm{pp}$.

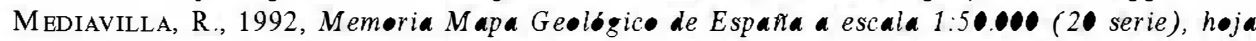
de La Vellés (n1 452). Publications Instituto Tecnológico Geominero de España (Madrid, Spain), in press.

Megias, A. G., 1982, Introducción al análisis tectosedimentario: aplicación al estudio dinámico

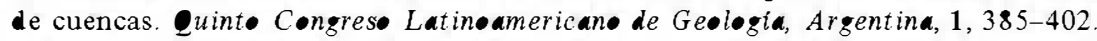

MilleR, N. L., and Elvidge, C. D., 1985, The iron absorption index: a comparison of ratiobased and baseline-based techniques for the mapping of iron oxides. Proceedings

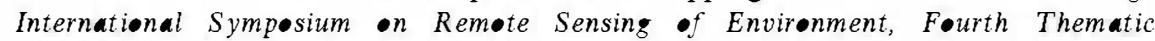

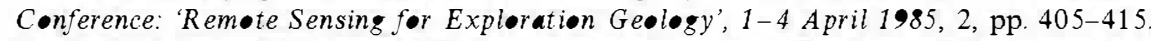

Peters, D. C., 1983, Use of airborne MSS data to map alteration related to roll-front uranium

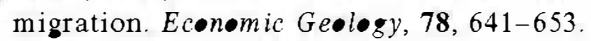


P•Dwysøcki, M. H., SegAL, D. B., and Abrams, M. J., 1983, Use of multispectral scanner images for assessment of hydrothermal alteration in the Marysvale, Utah, mining area.

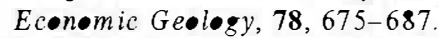

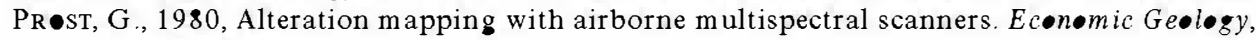
75, 894-906.

RiAZA, A., 1988, Evaluación preliminar de una imagen TM para la cartografía de rocas volcánicas. Resúmenes II Reunión del Grup• de Trabaj• en Teledetección, Valencia, 17-18 Diciembre 1987, pp. 53-69.

Riaza, A., Mediavilla, R., Santisteban, J. L., Villar, P., and Martin Alfageme, S., 1995, Regolitos en una cuenca terciaria. Propiedades espectrales según su mineralogia en función de la evolución climática. C•løqui Internacional søbre Prøpiedades espectrales $y$ teledetección de los suelos y rocas del visible al infrarroj• mediø, La Serena (Chile), 24-27 de Abril 1995, pp. 100-104.

Rivard, B., Arvidsøn, R. E., Duncan, I. J., Sultan, M., and El Kaliøuby, B., 1992, Varnish, sediment and rock controls on spectral reflectance of outcrops in arid regions. Ge $\log y$, 20, 295-298

R॰WAN, L. C., and KAHLE, A. B., 1982, Evaluation of 0.46 to $2.36 \mu \mathrm{m}$ multispectral scanner images of the East Tintic mining district, Utah, for mapping hydrothermally altered

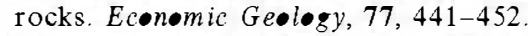

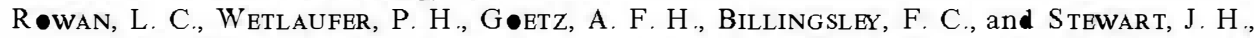
1976, Discrimination of rock types and detection of hydrothermally altered areas in south-central Nevada by the use of computer-enhanced ER TS images. United States

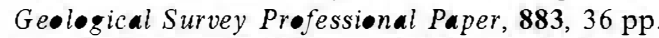

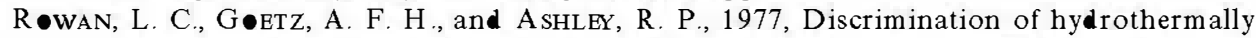
altered and unaltered rocks in the visible and near infrared multispectral images. Ge•physics, 42, 522-535.

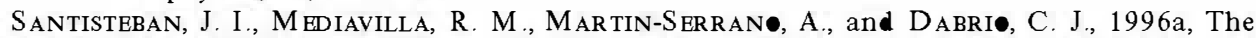
Duero Basin: a general overview. In Tertiary Basins of Spain, edited by P. Friend and C. J. Dabrio (Cambridge: Cambridge University Press), pp. 183-187.

Santisteban, J. I., Martin-Serrane, A., Mediavilla, R. M., and Dabriø, C. J., 1996b, Southwestern Duero and Ciudad Rodrigo basins: infill and dissection of a Tertiary basin. In Tertiary Basins of Spain, edited by P. Friend and C. J. Dabrio (Cambridge: Cambridge University Press), pp. 196-202.

SEGAL, D. B., 1982, Theoretical basis for differentiation of ferric-iron bearing minerals using

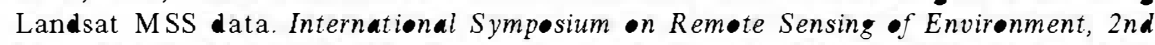

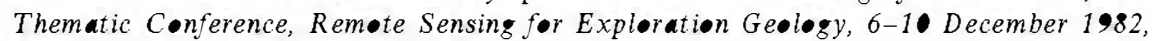
F•rt W•rth, Texas, II, pp. 949-951.

SEGAL, D. B., 1983, Use of Landsat multispectral scanner data for the definition of limonitic

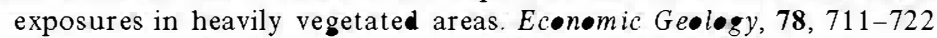

SINGER, R. B., 1981, Near-infrared spectral reflectance of mineral mixtures: systematic com binations of pyroxenes, olivine and iron oxides. Jøurnal of Gephysical Research, 86, 7967-7982.

T॰WNSEND, T. E., 1987, Discrimination of iron alteration minerals in visible and near-infrared

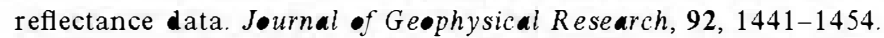

White, K., WALDEN, J., and R $\bullet L L I N$, E., 1992, Remote sensing of pedogenic iron oxides using Landsat Thematic Mapper data of Southern Tunisia. 18th Annual Conference of the

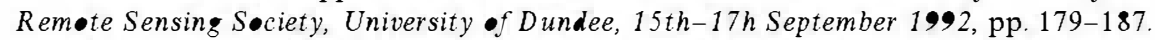

White W. B., and KeESTER, K. L., 1966, Optical absorption spectra of iron in the rock forming silicates. American Mineralogist, 51, 774-791. 